\title{
Single Beat QTCB Interval
}

National Cancer Institute

\section{Source}

National Cancer Institute. Single Beat QTCB Interval. NCI Thesaurus. Code C117785.

A QT single beat interval corrected for heart rate using Bazett's formula. 